\title{
Archetypes: The Contribution of Individual Psychology to Cross-cultural Symbolism
}

\author{
Erik D. Goodwyn
}

\begin{abstract}
When a patient reports a dream or undirected fantasy in psychotherapy, classical Jungian technique includes, among other things, comparing this material to that of cross-cultural symbolism (CCS). The validity of this aspect of the method hinges on what we think the origin of CCS is. If we believe that the lion's share of such content comes from specific universal tendencies of the individual psyche, then it is reasonable to look to CCS as a source of clinical interpretive information. If not, however, the method loses credibility. An examination of this comparison reveals that some discussions about archetypes have been plagued by a false dichotomy of biology vs. emergence. Addressing this problem helps to organize various theories about archetypes that compare CCS into a more productive dialogue.
\end{abstract}

Keywords: anthropology, archetype, cross-cultural symbolism, emergence, genetics, Jung, phenomenology, self-organization

\section{Myths and Dreams}

Consider that there is a "Beauty and the Beast" type story in the folklore of nearly every culture studied around the world. Folklorists classify the Beauty and the Beast story as Aarne-Thompson-Uther (ATU) type 425C (Üther, 2011), which unfolds as follows: a merchant embarks on a trip intending to bring back three gifts for his daughters. The older two demand jewelry and clothing, but the youngest one asks for a rose. The merchant gets lost and stays in a deserted castle/house where he finally finds a rose. There, an animal/monster (who is sometimes invisible) demands that the merchant return or send a substitute. The youngest daughter volunteers to take his place but refuses to marry the ugly/invisible creature, who is nevertheless kind to her. She then sees her father (often with a magic mirror) ill, and she is allowed to visit him, but her envious sisters conspire to make her overstay her allotted visitation time. When she returns and finds the creature near death, she realizes she loves him and so caresses/kisses him, which breaks the spell and reveals his true self as a handsome prince/etc. They marry.

Versions of the ATU 425C story have been found (Üther 2011: 252) in Finland, Sweden, Estonia, Latvia, Lithuania, Denmark, the Faeroes, England, Spain, Portugal, the Netherlands, Germany, Italy, Sardinia, Malta, Hungary, Czechoslovakia, Serbia, Romania, Bulgaria, Poland, Russia, Ukraine, Turkey, Mordvinia, Yakutsk, Mongolia, Georgia, India, China, Japan, the Americas, the Dominican Republic, Colombia, Brazil, Egypt, Tunisia, and Morocco among others. Some linguists even claim that the Indo-European versions of this story are likely to be at least 2500 to 6000 years old (da Silva and Tehrani, 2016: 8).

The following dream was reported in therapy by 35-year old woman, "Ms. A":

I've been "married off" to a man in a big house on a hill in another state. I'm pretty reluctant to go, but I have to-it's weird, I feel like I have to do 
it to help my dad for some reason, to make him happy or something. Anyway, when I get there the house is really dark and my husband is "in the shadows" all the time. I can't see him. I'm supposed to be married to this guy but I can just hear his voice.

Obviously this dream bears more than a passing resemblance to a significant part of the above ATU 425C story. Suppose for the sake of argument that this patient has never seen or read any version of the Beauty and the Beast story. Does the fact that she has dreamed a part of a story that may be thousands of years old and told in every corner of the globe have any clinical significance? On the other hand, supposed she had heard a version of it: does that change our interpretation? If so, why? A good deal of empirical dream science (reviewed in depth in Goodwyn, 2018, pp. 1-54) supports the notion that dreams are nonrandom constructions of the psyche that (except in the case of severe trauma) do not simply carbon-copy memories. Therefore, it stands to reason that there is a non-trivial relationship between dreams and fairly-tale or mythic motifs, especially in the case of creating a narrative with similarity to a fairy tale never encountered. How closely, then, should we consider a dream to an independently invented story or collection of motifs?

\section{Cross-cultural Symbols}

Jung defined the archetype in many ways; one of his most mature definitions of the archetype tied it to recurrent mythic motifs. The archetype-as-such, in this case, is "an inherited tendency of the human mind to form representations of mythological motifsrepresentations that vary a great deal without losing their basic pattern.” (1950/1977, para. 523). The present essay is concerned with comparing models of the archetype along a different axis than has been done up to this point. The reason is that the above definition and others like it assume that we can use mythological motifs to inform clinical interpretation. However, often archetype models do not focus on this particular issue (Goodwyn, 2013).

Classic Jungian technique assumes that we can use cross cultural symbols (CCS hereafter) to help us understand the meaning of Ms. A.'s dream (Jung, 1954; Jung \& Meyer-Grass, 2008; McGuire, 1984). Examples of CCS of myth and ritual are abundant (ARAS, 2010; Bierlein, 1994; Cirlot, 2002; Eliade, 1958; Frazer, 1921; Lévi-Strauss, 1955; Sproul, 1979; Tresidder, 2005; Van Gennep, 1960, and of course throughout Jung's Collected Works). These include the tendency to view water as a symbol of life; the use of red and/or fire as a symbol of intense affect; mandalas as symbols of balance and integration; rabbits as symbols of fertility; birds as symbols of divine messages; darkness as symbolic of evil, the unknown, or fertile potential; light as symbol of truth/life/knowledge; height and wind as a symbol of divinity; large trees as symbols of the cosmos; caves as symbols gestation; snakes as symbols of rebirth; doorways as points of transition in social state; synchronized behavior as a symbol of psychological/spiritual unity, etc. Examples could easily be multiplied.

CCS means symbolic associations that find their way into many mythic and folkloric traditions spread across large spans of space and history. However, I am focusing on particular associations (like darkness = unknown), however, not fully-formed symbols, which can of course vary across cultures; e.g., the dragon appears in many cultures, but only certain associations with it (reptilian = primal, size $=$ importance, etc.) appear to be 
truly universal, whereas the full meaning of the dragon is different in Europe as opposed to, say, China. Moreover, this is not to say that the classical technique involves making simple-minded one-to-one correlations between a dream and the above CCS. That would not be representative of Jung's approach, which was more nuanced:

It does not, of course, suffice simply to connect a dream about a snake with the mythological occurrence of snakes, for who is to guarantee that the functional meaning of the snake in the dream is the same as in the mythological setting: In order to draw a valid parallel, it is necessary to know the functional meaning of the individual symbol, and then to find out whether the apparently parallel mythological symbol has a similar context and therefore the same functional meaning. (Jung, 1959/2006, para 103)

Thus, Jung's method called for looking at the context of when Ms. A's dream occurred, and what her personal history up to this point was, in addition to looking at the fairy tale for amplifications. It is this last bit that I am concerned with here-the comparison of a dream with a folktale. If we are to base our practices on sound theory, we must recognize that this latter technique of making any reference to CCS at all requires that there should at least be some kind of established theoretical connection between the individual psyche and CCS. Jung proposed that this connection was the archetype itself.

The phenomenon of CCS is therefore central to the validity of this aspect of the classical technique and to the archetype as a theoretical concept. How we choose to explain this phenomenon is of clinical importance. If we feel CCS is caused by factors within the individual psyche like archetypes, then there is a strong connection between them, and so if my patient has a dream or persistent fantasy involving birds, darkness, caves, and a big tree, I should consider the CCS as source of possible meaning for such material because they're likely to be using the same symbolic associations. But to say "they're likely to" means I must assume Jung's premise: that the human psyche contains innate archetypes that manifest as tendencies to form such material. On the other hand, if I believe CCS does not have much to do with individual psychology, then such pursuit loses its justification and validity, and we should not engage in this aspect of the classical approach - at least not for this reason, anyway.

Note that regardless of theory, therapists and patients can always use myths and folktales in unique ways to achieve clinical gains. But this fact does not inform us as to the validity of Jung's proposal in the first place. This question is therefore a theoretical one rather than a technique-based concern. Though comparing Ms. A's dream to the Beauty and the Beast story can be clinically useful, what concerns this essay is the validity of Jung's claim that archetypes exist universally within each human psyche, and that moreover they are responsible for the phenomenon of CCS. Is part of the reason Ms. A dreamed this story-structure because we all have an unconscious, innate tendency to formulate ideas into particular patterns - patterns that are found in worldwide myths and folktales?

Likewise, while some authors offer much deeper meditations on archetypes as they relate to the nature of the psychoid, the spirit, the underlying non-differentiation of self and other, and the characteristics of synchronicity (Addison, 2016; Bright, 2009; Connolly, 2015), the present essay is more prosaic and humble in its aspirations. What, if anything, does the individual psyche (whatever psyche may actually be, if it is indeed possible to 
know) have to contribute to the construction of CCS and what can that tell us about archetypes, as defined in this particular context? This question focuses on a simpler issue regarding the origin of CCS that I feel has direct clinical relevance, but it is also of broader interest outside the consulting room: if Jung was wrong about the existence of archetypes (however they may be further defined), how then do we explain the phenomenon of CCS?

\section{The Role of the Individual Psyche}

Starting theory with the facts of CCS (as Jung himself did) can be a useful springboard for thinking on archetypes (Goodwyn, 2013). CCS is a given-again, at the basic imageassociation level, not necessarily the fully formed symbol level—so there is a need to explain why it occurs, not only as a general question, but also because it relates to clinical technique. Scholarship here has been difficult due to historical interdisciplinary academic divisions (Goodwyn, 2014). Nevertheless, to answer it we will need to look closer at what exactly Jung was proposing. Classically, Jungian theory proposes that the individual psyche makes a very active contribution to the complex processes that give rise to CCS. That is, Jung proposed that each person has a strong tendency to make and/or selectively retain certain unconscious symbolic associations (like light $=$ truth/knowledge, flowing water $=$ purification, snake $=$ rebirth, etc.). This fact is why they can and do appear nearly everywhere. If true, we are justified in using such symbolism to help understand patients who come to with imagery in dreams and undirected fantasy material of light or snakes or whatever. Then we must take into account the patient's individual context and history, as Jung advises in the above quotation and many others like it-but we cannot start here if there is no reason to believe CCS is created in some significant measure by innate psychological factors.

Jung was unfortunately very vague on the details of how this is supposed to work, though this is for understandable reasons given what he was studying. Nevertheless, saying that archetypes cause CCS only tells us that there is something about the innate structure of the individual mind that contributes to CCS, but sparse detail is provided on what exactly that might be. This is both a consequence of his not having the available data at his disposal, and also likely due to his personality and overall intuitive approach. The last few decades, however, have given us more data to work with, which have resulted in a number of attempts to answer this question.

\section{What Creates CCS?}

While many authors have of course discussed the archetype, there are only a few that need occupy us here: those who specifically discuss the relationship of individual psyche to CCS and the related debate over the existence or non-existence of the archetype. There have been many models that say the archetype is an extant and necessary part of the human mind that furthermore specifies the source of the "natural tendency" Jung speaks of to create CCS. Theorists such as Anthony Stevens (2003), John Haule (2011), and Goodwyn (2012) have hypothesized a variety of biological and evolutionary mechanisms to account for them. According to this approach, archetypes exist and are likely composed of a variety of inborn tendencies acting in concert that are related to our evolutionary history. Snakes, for example, appear often in CCS partially because they are ancient dangers to homo sapiens. Throughout our history as a species, it became advantageous to single out snake-like 
imagery in the environment, so the effect of this long history is an inborn tendency to create snake symbols and tell stories about snake-like creatures. Snakes are therefore fascinating and possibly terrifying (and so good symbols for the numinous) in part because of our biological history (for further discussion, see Goodwyn, 2012, pp. 69-72).

Some object to such an approach. Some raise concerns that biological approaches seem to underestimate the importance of complex developmental events that give rise to emergent psychological qualities. Some theorists also argue that it is implausible to assume that symbolic information could be encoded in genes or brain structures (objections reviewed by Roesler, 2012). Still others (Colman, 2018b) have said that biological theorists such as myself have attacked a straw man in claiming that under-emphasizing biological contributors is tantamount to the acceptance of the outdated tabula rasa model of the psyche (discussed below).

In any case, those who object to the biological account of archetypes and CCS instead propose that what we inherit biologically may be far too non-specific to be held directly responsible for CCS, preferring to argue that while there are basic innate/biological starting points, many psychic contents are more properly attributed to emergent and relational factors, arising in the complex interplay of child and caretaker/micro-culture, essentially leaving the genome behind. To these objectors, biology provides only the basic infrastructure of the psyche, but it does no further significant work from theredevelopment and immersion in cultural context does the rest. Here, the ubiquity of snake imagery might presumably come not from an innate predisposition to recognize and have an emotional response to snake-like imagery or to relate it to rebirth/etc., but rather from the ubiquity of snakes themselves, along with early developmental imitative learning of snake fears/attentional biases, and early primitive association of snake imagery with symbolic themes due to repeated cultural exposure to such ideas.

Importantly, however, for some authors the emergentist proposal means we must abandon the concept of archetypes as outdated and unnecessary (Saunders and Skar, 2001; Merchant, 2009; Colman, 2016, 2018a). The latter opinion is not shared by all such theorists, and in any case it is a separate issue. Acknowledging important selforganizing/emergent qualities of the psyche is not equivalent to claiming archetypes do not exist. Understood properly, the biological and emergentist explanation for the origin of archetypes are not mutually exclusive.

To recap, then, some theorists propose that CCS can be explained by archetypesinherited tendencies to create story forms with CCS embedded in them-which themselves are composed, at least in part, by a collection of biological/evolution based psychological processes. Others de-emphasize the role of biology in favor of a constructivist or emergentist origin for the archetypes, proposing that CCS is absorbed by the developing psyche and ingrained through self-organization and cultural immersion. These latter models define the archetype in more or less non-biological terms, or they argue that emergentist arguments sufficiently obviate the need for the archetype altogether as an explanation for human experience.

\section{The Biological versus Emergentist Debate}

The above biological vs emergentist classification has occupied archetype scholarship in the last few years. I believe, however, that this classification scheme presents a sneaky false 
dichotomy. The deceptive nature of this dichotomy can be seen in the debate about "innateness" that occurred back in 2010 involving myself, Knox (2010), Merchant (2010), and Hogenson (2010). At that time, the debate centered on whether or not the psyche had any innate qualities or foundations versus the dreaded tabula rasa formulation. Unfortunately, for my part I helped to frame the debate that way-my position originally was critical of emergentism on that basis-but I was wrong on that particular point, and I soon saw that the two camps were talking past one another. As Colman (2018b) states: "emergence theory in no way contradicts the belief in innate qualities - rather it provides a much more sophisticated and scientifically up to date account of how very simple forms of organization can develop into complex psycho-social capacities. . . ” (p. 668).

No reasonable theorist can contest this fact, and Colman was right to characterize the tabula rasa accusation as a straw-man. Yet, Colman finished the above statement with "without any of this needing to be coded in the genes" (p. 668). Here is where it gets sticky, and the real flaw is shown in the model. Once we recognize the flaw and fix it, we see that the biological and emergentist paradigms are not mutually exclusive at all. As the original emergentist argument goes, the genome sets up a very primitive array of reflexive behaviors. In one paradigmatic example, originating with Knox (2003), and built upon by Merchant (2009), and later Colman (2016), is the infant “burst-pause” feeding reflex. Upon this innate reflex, it is argued, a rhythm is created in which, in conjunction with early experience with caretakers, a set of emergent characteristics build upon the "genetic" programs to create higher levels of complex behavior, but these emergent qualities leave those primitive programs behind as greater and greater complexity develops in the system. Therefor Colman says the subsequent developments need not be "coded in the genes".

But, with respect, this characterization of genetics is simply flat-out wrong. And while it is true that self-organization and emergent properties are undeniably a part of psychic development, the genome never stops playing a part in it at any point in our lives. With extremely rare exception, the genome of every single cell in the body continually feeds back into the development of the organism as a whole. This is the fatal flaw in the original emergentist model that forces a false opposition to biological/evolutionary arguments- the assumption that the genome simply jump starts the organism but then lets it go from there, allowing the environment to do the rest of the work. Biological development does not work in this manner. The genome codes for proteins which detect environmental changes that modify those proteins. They then feed back into the genome and modify how it expresses subsequent proteins-and so on, and so on, into incredibly complex systems that nonetheless never free themselves from genetic influence. Subsequent emergent properties are detected, responded to, and modified by the genome from birth until death. Most importantly, more often than not the same gene which codes for proteins involved in early primitive reflexive behavior can and will interact with subsequent development at progressively greater levels of complexity, applying new influence into the new level of complex development (see MacDougall-Shackleton, 2011, for a review with many examples).

In humans, just to use one example among a great many, the gene that codes for brainderived neurotrophic factor (BDNF) operates during very early development to modulate neuronal proliferation and pruning in neonates, but it operates continually throughout life, influencing functions at progressively higher levels of complexity. Later in life, the 
presence of BDNF is correlated with the maintenance of good memory function, the facilitation of learning and the promotion of neurogenesis in response to injury, and the maintenance of disease resistance. BDNF production responds to various psychological and physiological factors throughout life such as exercise, meditation, intellectual puzzlesolving tasks, and caloric restriction (see Rothman \& Mattson 2012, many other examples abound in the literature). The brain and psyche, then, never free themselves from the influence of this gene. Other examples abound: the genome alters its genetic expression in response to many psychotropic medications (i.e., Miyamoto et al, 2008, p. 2161-2162) and psychotherapy itself also triggers alterations in gene expression (Kay \& Kay 2008, p. 18701871). Whatever happens to us, the genome has something to say about it. These examples could be easily multiplied in terms of showing how the genome continues to influence development across a person's lifespan.

So am I saying, then, that "archetypes are encoded in genes"? That depends on what one means by “encode”. Genes code for proteins, not image or story structures. Nevertheless, story structures may still be the ultimate consequence of the way in which those genes play out. Therefore the influence of the genome never goes away, so the evolutionary principles shaped it can be reasonably assumed to play their part at every level of complexity, even if it doesn't play out as a rigid algorithm, adaptation or module, but instead acts more as a collection of constraints or biases that-in conjunction with universal environmental factors-guide and influence the self-organization of the psyche, in particular archetypal images and story structures that give rise to CCS. Clearly the exact mechanisms of how genes might affect psyche are yet to be worked out, and due to the immense complexity of the process - not to mention the mind-body problem - such mechanisms may never be. Furthermore, how all this might be interweaved into the idea of the spirit and spirituality is yet another deep question (indeed, the genome itself may be more spiritual than initial inspection reveals). But ultimately none of these challenges mean that genomic and evolutionary influence can be reduced to that of a mere spring-board for subsequent gene-free development. It cannot: it is always there, exerting its influence on development from before birth until death.

In any case, these data shows that the emergentist and biological models are not mutually contradictory-so long as we recognize that both processes operate to influence psychic development throughout the lifespan. And it is therefore possible that genomic influence, because it is life-spanning, may play a significant part in the self-organization and emergence of CCS, so long as we are careful not try to reduce psyche to biology. Eliminating the above mischaracterization of genetics from the emergentist paradigm reveals the biological and emergentist models can be complementary. Thus, the source of this debate is actually in the terms of causal explanation used: biological and emergentist explanations are usually operating on different explanatory levels. Whereas the biological/evolutionary explanations tend to look at function, the emergentist/developmental explanations tend to look at mechanism. In Aristotelian terms, evolutionary explanations favor final causes, whereas emergentist accounts favor efficient causes (naturally there is overlap). The understanding of causal explanation has been applied to ethology, where "explanatory levels" are used to conceptualize the understanding of animal behavior (excellent review in MacDougall-Shackleton 2011), and in fact this scheme has been applied to the psyche by of course none other than Jung himself 
(1960, para. 456, 493) — though he did not elaborate on the idea very much. Perhaps he should have. In any case, identifying the exact mechanism behind the development of the conversational rhythm, as it emerges from 'burst-pause,' patterns of neonatal feeding in no way contradicts the evolutionary account of the influence of the genome on this pattern at every point in development. Neither does the observation of the importance of selforganization and emergence rule out continued genetic influence at progressively higher levels of complexity. Rather, both explanatory accounts, properly contextualized, inform one another.

The above false dichotomy (biology vs emergence) does not really help us parse out the question of whether or not archetypes exist and/or elucidate the connection (if there is one) between the individual psyche and CCS. To move the discussion forward, we need to organize models along a different frame that is not a false dichotomy.

\section{Active and Passive Models}

Instead we need to examine this discussion in terms of how each model specifically connects (or doesn't connect) the individual psyche to CCS. Is the individual psyche an internally and independently active contributor in the creation of CCS? In other words, where some models propose that because of various factors including genes and emergent developments, the individual psyche has a strong internal tendency to produce CCS regardless of culture of origin, other models propose that the individual psyche has a relatively minor contribution to CCS, which means that CCS originates from some other source. For these models, CCS might, say, be an emergent property of societies rather than individuals. The former type of model let us call an "active" model, and the latter a "passive" model.

Each type of model has its own task to accomplish. Since active models assume that the individual psyche has some kind of reliably emergent universal characteristics that subsequently give rise to CCS, active models are the only ones that require archetypeshowever defined-as explanatory factors, and the definition for the archetype must be given in terms that are causally powerful enough and specific enough to produce a CCSmaking tendency. Passive models do not have to do any of this since they assume no such influence of the individual psyche on CCS. Instead, passive models must provide an explanation for where CCS comes from that does not depend on the individual psyche. Both types of model, then, have to deal with CCS one way or another, and only the active type of model justifies comparing dream/vision material with CCS as a result of foundational theoretical principles rather than some other reason (such as clinical utility). As mentioned earlier, only some of the theories on archetypes are relevant to the present discussion. Theories that discuss how archetypes or CCS is used in therapy but remain agnostic on the origins of CCS are not relevant here. Theories that discuss or define archetypes but do not directly address how those archetypes contribute to CCS are not relevant either-though with sufficient theoretical elaboration they easily could be. As it stands, there appears to be only a handful of theories at present that even remotely attempt to link the individual psyche to CCS, and so are relevant to the discussion at hand.

But is this framework a false dichotomy? Of those theories relevant to the present essay, are there theories that might be both active and passive? No: the use of the term "active" in this context is only referring to an innate tendency. This was chosen because of 
the definition Jung gave of the archetype: an innate tendency to form story-structures and imagery containing CCS. If we had defined "active" to mean models of the psyche which automatically produce snake imagery every time, then there would be room for a middleground category: a model that takes the psyche to make snake images "sometimes". But "sometimes" is what "tendency" means already. Jung never proposed an "always” model. Thus, either the psyche has an innate tendency to make CCS or the psyche doesn't. It would be contradictory to have a psyche which both has the tendency to make CCS and also not have the tendency. Even if our statement was "has the tendency sometimes" that would still only be a less frequent "tendency" and so even then such a model would still count as active. The current framework for understanding theories of psyche, then, should be more useful than the biology vs emergentist framework.

\section{Evaluating the Current Theories of Archetype within this Framework}

Classifying models of archetype along these lines helps to eliminate the biology-emergence false dichotomy and orient them in terms of what further work they need to do; thinking this way also reveals that some models previously opposed are actually aligned. As mentioned, we are focusing solely on models that specifically address the individual psyche-CCS link in order to evaluate the theoretical validity of considering CCS as informing clinical dream/vision material in psychotherapy. Other questions about the archetype, such as its metaphysical manifestation, the idea of the psychoid, the relation to synchronicity etc., should be left out of the discussion for now. Perhaps those characterizations of archetype can be aligned with the present mundane one (as Jung thought), and perhaps not. We will shelve that question for the time being.

In any case, if subsequent scholarship shows that the psyche is indeed active in the construction of CCS, then not only is the classical comparative method foundationally valid, the factors identified in this process can be used to define the archetype beyond Jung's frustratingly impressionistic definition. If, on the other hand, scholarship finds the psyche is actually passive with respect to CCS, then the archetype becomes a superfluous concept and we must base comparison of clinical material to CCS on some other theoretical or therapeutic principle, if at all.

So-called "biological" theories of myself, Anthony Stevens (2003), and John Haule (2011) are obviously active models, since they focus on how evolution has shaped the human psyche to a significant degree. Examples in this body of work abound, of ways in which innate qualities directly contribute to CCS, like the one given above regarding the snake image. Elsewhere, McDowell (2001), proposes that the archetype-as-such is an $a$ priori mathematical principle of self-organization that operates on dynamic systems such as the personality, and he furthermore links these principles to the CCS of the witch character. McDowell's model is therefore also an active one. The task, then, for both of these models is to provide more and more detail on the specific links between innate qualities and CCS.

Other models invoke self-organization, such as that of Saunders and Skar (2001) which note that the behavior of self-organizing dynamic systems appear to behave similarly to the way complexes do in the psyche. But the model of Saunders and Skar shows how ubiquitous complexes emerge, such as the Shadow or Anima, but they do not address CCS directly, so without clarification this theory is not analyzable in the present classification 
scheme. Hogenson (2009) argues for a role of self-organization in more general terms, but again, does not address CCS directly, instead staying more abstract in his discussion. I feel both of these models could address CCS more directly, but leave it to those authors to do so.

Colman (2016), takes the manifestly self-organizing character of various systems, and, accepting the error that Knox makes about genes merely providing simple nonrepresentational mechanisms and nothing else, he produces a model of the psyche without archetypes at all. Rather, he proposes a model of the psyche-embedded-in-culture, whereupon symbols are spontaneously and reliably emergent "without requiring an underlying principle” (Colman, 2016, p. 29). He gives as reasons for this maneuver the numerous inconsistencies in Jung's discourse on the archetype, along with the general vagueness of characterization and processes that are supposed to constitute the archetypeas-such. In any case, for Colman, symbols do not derive from content-free archetypes-assuch, but rather simply emerge from in between the actions of humans in society performing various activities. Concerned that many theories attempt to reduce archetypal images to merely the sum of their parts (whether it be biology, brains, or whatever), and recognizing the undeniably holistic character that symbols have, he concludes that the archetype-as-such, as principle "behind" the archetypal images, is a superfluous concept. Instead archetypal, or reliably repeated images, simply emerge from the complex interplay of psyche, body, culture, etc., without the need for any explanatory principle or a priori grounding.

Colman's formulation therefore leans heavily on the concept of "emergence": this concept-dating back as far as Aristotle-highlights the fact that complex systems at conditions far from equilibrium (like brains and probably the psyche) often display novel holistic properties that subsequently determine the behavior of the system in a top-down manner. Both he and Saunders and Skar assert that such self-organizing systems spontaneously display new and "emergent" properties without having any pre-existent "template" or "form" to follow, hence the logical conclusion that archetypes-as-such do not exist. There is a lot to value in Colman's approach, but more work could be done, particularly in defining what exactly is meant by "emergence" in the first place. The concept of emergence has gained a renewed interest in philosophy since the 1990s, but frequently the term is used with little discipline. Colman's use of the term feels intuitively correct, but it is simply a given and he does not delve into the various debates on the concept of emergence (such as that found in Kim 2006), and how it may or may not work within his model.

Moreover, the overall enterprise is plagued by the perpetuation of the mischaracterization of genetics that afflicted Knox's earlier work on archetypes. This might undermine the enterprise as a whole, or it may not-it's hard to say. In any case, Colman takes this emergentist idea one step further, excluding any "behindology" that seeks underlying structure or principles and focuses on an appreciation of the symbol in all its rich experiential glory. He dismisses the idea that the categorization of similar symbols represents anything more than an "abstraction".

The strongly anti-reductive power of this approach is valuable, but it does not require that we abandon all efforts to find underlying structural causes or features. Furthermore, the dismissal of forms as "abstractions" naturally imports a very old philosophical 
argument-pitting Colman as Aristotle against Jung's Plato. To really address this issue would require us to unpack a large body of metaphysical thought we cannot field here due to space constraints, but it is one I touch on elsewhere (2019). Nevertheless, McDowell has already provided an answer by identifying the organizing principles of emergent systems as essentially mathematical in nature. The problem here, of course, is that he shifts the debate from metaphysics to the philosophy of mathematics - also a weighty subject we cannot fully address here. In any case, Colman's formulation has great strengths and only a few weaknesses, but whatever one's opinion of it is, since his theory does not identify any organizing principles in the individual that might contribute to CCS (indeed he might argue that there is no such thing as "the individual", claiming it to be almost entirely culturally constituted), but instead argues that CCS are spontaneously emergent without any organizing principles, we can correctly classify his theory as a "passive" one. Thus, in the current framework, Colman's only task would be to explain how CCS "emerges" without referring to specific innate qualities. One way might be to follow the "hard" emergentism of philosopher C. D. Broad (1925), for whom emergent properties are ontological in nature, in which case they become brute facts. This is a philosophically defensible position, but it leaves us unable to determine why some symbols are crossculturally appearing and others are not. Other "softer" types of emergentism (like Freeman 2000), of course, might not necessarily have such a problem. It is hoped that Colman will build upon his promising emergent theory and address these concerns.

Knox’s (2003) archetype-as-image-schema model is recognized by Roesler (2013) and Colman (2016) for being an important attempt at reconciling the various models of archetype Jung seemed to vacillate between. They also recognize that image schemas are far removed from the full-blooded CCS we are used to associating archetypes with. Such a conclusion is necessitated by Knox's mischaracterization of genetics, but regardless of what one might think of that criticism, it remains that Knox's model appears to qualify as "passive", as it postulates only general, extremely abstract and non-specific contributions from the individual psyche and leaves the rest to culture/environment-it therefore does not propose a strong causal tendency of the individual to independently generate CCS. In this framework, then, Knox would need to address how CCS develops in fuller detail.

Pietikainen (1998) offers a passive theory of psyche that does indeed address the formation of CCS, claiming that it could be due to similarities in the contingencies of history and cultural practice across cultures rather than any individual psychological tendency. This sounds quite reasonable on the surface; unfortunately, Pietikainen does not provide any concrete examples to bolster his case, preferring to leave such explanatory principles rather vague. One would hope that later scholarship might explain, for example, what historical contingency or practice might lead rituals worldwide to selectively utilize the colors red, black, and white (Turner, 1974) with such regularity, or why might it occur not only to ancient Europeans (LeCouteux, 1996, pp. 32-44) but the Tlinglit (Kan, 2009) and several Indonesian peoples (Hertz, 2009) that the dead should leave the house where death occurred through an unusual opening that was then rapidly closed up after. Pietikainen offers no such specifics. Nevertheless, this model appears to have promise, and so I hope later scholarship might take up this task.

Finally, it should be recognized that it is possible to construct a passive biological model. One could argue, for example, that the combination of well documented and innate 
emotional systems identified by affective neuroscientists (Panksepp 1998, 2005; Alcaro et al 2017), combined with the well-known brain capacity for cross-modal plasticity represent the entire repertoire of innate psychic qualities needed, denying that there are any CCSspecific tendencies in the psyche. As in the other cases, then, the task would be to explain how CCS arises within this paradigm. As I believe there are innate CCS-specific tendencies, I would not be defending such a model, but I recognize it is a viable possibility that deserves attention.

\section{Conclusion}

We focused on the classical Jungian technique of using CCS such as snake $=$ rebirth, wind $=$ spirit, giant trees $=$ the cosmos, etc., to suggest (but of course not dictate) interpretations of clinical data reported to us in the consulting room. The validity of this technique and the nature of the archetype as a conceptually useful construct depends upon what we think the source of CCS is. If we think the individual human psyche has strong tendencies to make and/or selectively retain CCS on its own with relatively little input from specific cultural surroundings and history, then we have what I label an "active" model of the psyche with respect to recurrent symbolic associations. Active models propose that the psyche makes these associations through the mechanisms of archetypes (which may or may not also have biological underpinnings, depending on the model). These archetypes are organizational principles of individual psychological experience, and since (in these models) they are ultimately responsible for the existence of CCS, we can assume comparing Ms. A.'s dreams to such symbolism is a reasonable clinical exercise that may yield some insight. If, on the other hand, the psyche is "passive" in the creation of recurrent symbols, meaning that the individual psyche does not universally develop anything so specific on its own, and CCS develops for some other non-individual-psyche mechanism, then the classic comparative exercise is not valid (at least for the reasons Jung gave, anyway), and moreover the term "archetype" must either be redefined, stripped of most of its causal powers, or simply be eliminated.

This leaves us with a way to organize models as falling into either active or passive categories with respect to the individual-CCS linkage, telling us what work each has to do. Active models must demonstrate how and what individual factors give rise to CCS, thereby helping to nail down a clearer definition of the archetype, and passive ones must demonstrate how CCS arises in the absence of such factors. Furthermore, because of the way Jung defined the archetype, passive models will be forced to either eliminate the archetype or dramatically redefine it, such that it may become unrecognizable to Jung's original intent. In any case, unlike the biological/emergentist dichotomy, the active/passive dichotomy does not appear to be a false dichotomy. Thus we learn what each type of model has to do, but it only applies to models that refer to CCS in some manner. In any case, my intent was only to show how categorizing models of archetype along these lines will help to either determine if archetypes (as tendencies to create CCS) exist beyond mere abstractions, and if so, what they are composed of.

\section{Contributor}

Dr. Goodwyn graduated from the University of Cincinnati College of Medicine to serve in the United States Air Force for seven years. He is now assistant professor of psychiatry 
and director of psychotherapy training at the University of Louisville. There he teaches medical students and residents psychotherapy, dream interpretation, and the intersection between psychiatry and anthropology, ritual scholarship, and neuroscience.

\section{References}

Addison, A. (2016). Jung's psychoid concept and Bion’s proto-mental concept: a comparison. Journal of Analytical Psychology 61(5): 567-587.

Alcaro, A., Carta, S., and Panksepp, J. (2017). The affective core of the self: a neuroarchetypical perspective on the foundations of human (and animal) subjectivity. Frontiers in Psychology 8: 1424. Doi: 2017 Sep 1;8:1424. doi: 10.3389/fpsyg.2017.01424. eCollection 2017.

ARAS (Archive for Research in Archetypal Symbolism). (2010). The Book of Symbols. New York, NY: Tascen.

Bierlein, J. F. (1994). Parallel Myths. New York, NY: Ballatine.

Bright, G. (2009). Regression in the countertransference: working with the archetype of the abandoned child. Journal of Analytical Psychology 54: 379 -394.

Broad, C. D. (1925). The mind and its place in nature. London, UK: Routledge and Kegan Paul.

Cirlot, J. E. (2002). A Dictionary of Symbols. New York, NY: Dover. (Original work published 1971)

Colman, W. (2016). Act and Image. New York, NY: Spring Books.

Colman, W. (2018a). Are archetypes essential? Journal of Analytical Psychology 63(3): 336-346.

Colman, W. (2018b). Response to Hugh Gee’s “a simple statement about the concept of archetypes. Journal of Analytical Psychology (63): 667-669.

Connolly, A. (2015). Bridging the reductive and the synthetic: some reflections on the clinical implications of synchronicity. Journal of Analytical Psychology 60(2): 159-178.

Da Silva, S. G. and Tehrani J. J. (2016). Comparative phylogenetic analyses uncover the ancient roots of Indo-European folktales. Royal Society Open Science 3: 150645. http://dx.doi.org/10.1098/rsos.150645.

Eliade, M. (1958). Patterns in Ccomparative religion. London, UK: Sheed and Ward.

Frazer, J. (1921). The golden bough. Oxford, UK: Oxford University Press.

Freeman, W. (2000). How Brains Make up their Minds. New York, NY: Columbia University Press.

Goodwyn, E. (2012). The Neurobiology of the Gods. New York, NY: Routledge.

Goodwyn, E. (2013). Recurrent motifs as resonant attractor states in the narrative field: a testable model of archetype. Journal of Analytical Psychology, 2013, 58: 387408.

Goodwyn, E. (2014). Depth Psychology and Symbolic Anthropology: Toward a Depth Sociology of Psychocultural Interaction. International Journal for the Psychology of Religion, 24(3), 169 -184. 
Goodwyn, E. (2018). Understanding Dreams and Other Spontaneous Images: the Invisible Storyteller. New York, NY: Routledge.

Goodwyn, E. (2019). The Mind-Body Problem in relation to Jung. In J. Mills (Ed.), Jung and Philosophy (working title). New York, NY: Routledge. Pages TBA.

Haule, J. (2011). Jung in the $21^{\text {st }}$ Century. 2 Vols. New York: Routledge.

Hertz, R. (2009). A contribution to the study of the collective representation of death. In A. C. G. M. Robben (Ed.), Death, Mourning and Burial: A Cross-Cultural Reader. Malden, MA: Blackwell, 197-212.

Hogenson, G. B. (2004). Archetypes: emergence and the psyche's deep structure. In J. Cambray and L. Carter (Eds.). Analytical Psychology: contemporary perspectives in Jungian Analysis . New York, NY: Brunner-Routledge.

Hogenson, G. B. (2009). Archetypes as action patterns. Journal of Analytical Psychology 54: 325-337.

Hogenson, G. B. (2010). Responses to Erik Goodwyn’s “Approaching archetypes: reconsidering innateness”. Journal of Analytical Psychology 55(4): 543-9.

Jung, C. G. (2006)The concept of the collective unconscious. .(R. F. C. Hull, Trans.). In H. Read et al. (Series Eds.), The collected works of C. G. Jung (Vol. 9, pt. 1, $2^{\text {nd }}$. Ed.,pp. 42-53). Princeton, NJ: Princeton University Press. (Original work published in 1959)

Jung, C. G. (1985). The practical use of dream analysis (R. F. C. Hull, Trans.).In H. Read et al. (Series Eds.), The collected works of C. G. Jung (Vol. 16, 2nd. Ed.,pp. 139162). Princeton, NJ: Princeton University Press. (Original work published in 1954).

Jung, C. G. ([1960]1975).General aspects of dream psychology (R. F. C. Hull, Trans.). In H. Read et al. (Series Eds.), The collected works of C. G. Jung (Vol. 8, 2nd. Ed.,pp. 237-280). Princeton, NJ: Princeton University Press. (Original work published in 1960).

Jung, C. G. (1977)The archetype in dream symbolism. In H. Read et al. (Series Eds.), The collected works of C. G. Jung (Vol. 18, 2nd. Ed.,pp. 227-243). Princeton, NJ: Princeton University Press. (Original work published in 1970).

Jung, L. \& Meyer-Grass, M. (Eds.). (2008). Children's Dreams: Notes from the seminar given in 1936-1940. Princeton: Princeton University Press.

Kan, S. (2009). The nineteenth-century Tlinglit Potlatch: a new perspective. In A. C. G. M. Robben (ed.), Death, Mourning and Burial: A Cross-Cultural Reader. Malden, MA: Blackwell, 286-302.

Kay, J., \& Kay, R. (2008). Individual psychoanalytic psychotherapy. In A. Tasman, J. Kay, J. A. Lieberman, M. B. First and M. Maj (Eds.) Psychiatry, $3^{\text {rd }}$ Edition, Vol 2: 1851-1874. West Sussex, UK: Wiley \& Sons.

Kim, J. (2006). Emergence: core ideas and issues. Synthese 151: 547-59.

Knox, J. (2003). Archetype, attachment, analysis. Hove, UK: Brunner-Routledge.

LeCouteux, C. (1996). The Return of the Dead. Rochester, VT: Inner Traditions.

Lévi-Strauss, C. (1976). Structural Anthropology. New York, NY: Basic Books. 
MacDougall-Shackleton, S., A. (2011). The levels of analysis revisited. Philosophical Transactions of the Royal Society B: Biological Sciences 366 (1574): 2076-2085.

Merchant, J. (2009). A reappraisal of classical archetype theory and its implications for theory and practice. Journal of Analytical Psychology 54 (3): 339-358.

Miyamoto, S., Merril, D. B., Lieberman, J. A., Fleischacker, W. W., and Marder, S. R. (2008). Antipsychotic drugs. In A. Tasman, J. Kay, J. A. Lieberman, M. B. First and M. Maj (Eds.). Psychiatry, $3^{\text {rd }}$ Edition, Vol 2: 2161-2201. West Sussex, UK: Wiley \& Sons.

McDowell, M. J. (2001). Principle of organization: a dynamic-systems view of the archetype-as-such. Journal of Analytical Psychology 46: 637-654.

McGuire, W. (Ed.). (1984). Dream Analysis: notes of the seminar given in 1928-1930. Princeton, NJ: Princeton University Press.

Panksepp, J. (1998). Affective Neuroscience: the Foundations of Human and Animal Emotions. Oxford, UK: Oxford University Press.

Panksepp J. (2005). Affective Consciousness: Core Emotional Feelings in Animals and Humans. Cognition and Consciousness 14: 30-80.

Pietikainen, P. (1998). Archetypes as symbolic forms. Journal of Analytical Psychology 43: 325-343.

Roesler, C. (2012). Are archetypes transmitted more by culture than biology? Journal of Analytical Psychology 57: 224-247.

Rothman, S. M., \& Mattson, M. P. (2012). Activity dependent, stress-responsive BDNF signaling and the quest for optimal brain health and resilience throughout the lifespan. Neuroscience (239): 228-240.

Saunders, P. \& Skar, P. (2001). Archetypes, complexes and self-organization. Journal of Analytical Psychology 46: 305-323.

Sproul, B. C. (1979). Primal Myths: Creation Myths Around the World. New York, NY: HarperOne.

Stevens, A. (2003). Archetype Revisited. London, UK: Routledge.

Tresidder, J. (ed.). (2005). The Complete Dictionary of Symbols. San Franscisco, CA: Chronicle.

Turner, V. (1974). Dramas, Fields, and Metaphors. Ithaca, NW: Cornell University Press.

Üther, H. J. (2004). The Types of International Folktales. Helsinki, FI: Finnish Academy of Science.

Van Gennep, A. (1960). The Rites of Passage. Chicago, IL: University of Chicago Press. 